\title{
Adult Central Nervous System Embryonal Tumor, Not Otherwise Specified
}

National Cancer Institute

\section{Source}

National Cancer Institute. Adult Central Nervous System Embryonal Tumor, Not

Otherwise Specified. NCI Thesaurus. Code C5411.

A central nervous system embryonal tumor, not otherwise specified that occurs in adults. 